modify them or to make some of them optional. In the county of Essex, for example, the medical officer of health convened a meeting of the rural district councils which resulted in a committee being formed to formulate the modifications desired and two councils inserted these modifications in their by-laws and submitted them to the Local Government Board for approval. The Board at first refused to consider the alterations and suggested that the councils should adopt some modified by-laws which they had prepared to meet the requirements of rural districts. It was found, however, that these referred only to drainage, closet accommodation, and so on, and did not touch the position and structure of the houses themselves. As the by-laws were more particularly required to prevent cottages being built, as they were then being built, of old packing cases, corrugated and galvanised iron, and the like, and often in positions where they appreciably affected the value of the adjoining property, the suggestion of the Board could not be accepted. Finally, after a good deal of influence had been brought to bear upon the President, two conferences were arranged between the representatives of the district councils and certain officials of the Board and a compromise was effected which now permits of cottages being erected in these districts of other than "hard and incombustible material properly bonded and solidly put together." 'l'hat this concession has been obtained does not appear to be known generally. The effect as yet is said not to be so marked as could have been desired and the impression is gaining ground that the stringency of the by-laws was merely made the excuse for not building cottages. since building operations have not been accelerated though complaints have ceased. The general ignorance of the public with reference to the work done by rural sanitary authorities probably arises in a great measure from the fact that the annual reports of the medical officers of health are either not printed or are merely distributed amongst the members of the councils. If these reports were made a little more interesting and were issued to the public they would serve as a valuable means of educating the people in matters pertaining to the public health and of dissipating some of the ignorance which now obtains as to the duties discharged by the councils. Moreover, it would make the members of the councils more anxious to discharge those duties faithfully if they knew that each year an impartial observer would record the results of their labours for the benefit of their constituents. Such reports to be of value must be, as has been abore observed, impartial in character and this impartiality can only be secured when every medical officer of health holds his office not during the will of the council but during that of some higher authority, such as the county councils or the Local Government Board. This, however, is a matter upon which we have so frequently commented that it is not necessary further to insist upon it in connexion with this subject. No doubt some good will accrue from the ventilation of Mr. Justice Grantham's grievances in the press, but on the whole such exaggerated statements as were made by members of the deputation to Mr. Long, and as have since appeared in the lay press, are calculated to do more harm than good; hence they are to be deplored, and it is to the interest of the good government of our rural communities that such statements should not be allowed to pass unchallenged.

THE great pressure on our space caused by the publication at length of the proceedings at the session of the General Medical Council has compelled us to delay presenting to our readers an adequate memoir of our late esteemed colleague Dr. G. V. Poore.

IN a risumé of an address delivered by Professor Koch before the Ierlin Medical Society upon Trypanosomiasis which we published in our issue of Nov. 12th an error was made which requires rectification. The discovery of the trypanosome in man in 1901 was attributed by our special correspondent to Dr. Forde, whereas Professor Koch ascribed the discovery, as has, we believe, been generally done in our columns and elsewhere, to Dr. Dutton.

THE triennial prize of $£ 300$ for 1904 has been awarded by the trustees under the will of the late Sir Astley P. Cooper, Bart., to Mr. W. S. Handley, M.S. Lond., for his essay on "The Pathology of Carcinoma and the Distribution and Frequency of Occurrence of the Secondary Deposits corre. sponding to the Various Primary Growths.'

THE annual dinner of the Otological Society of the United Kingdom will be held at the Trocadéro Restaurant, Piccadilly-circens, London, W., on Monday, Dec. 5th, at 7.30 P.M. Dr. Thomas Barr (the President) will occupy the chair. Information and tickets can be obtained from Dr. Herbert Tilley, 89, Harley-street, W.

As was generally believed would be the case Dr. Donald MacAlister, the representative of the University of Cambridge upon the General Medical Council, was elected President of the Council at the close of the session.

THE Earl of Rosebery, Chancellor of the University, has given $\$ 1000$ to the Institute of Medical Sciences Fund, University of London.

\section{A CONTRIBUTION TO THE STUDY OF THE TREATMENT OF HOSPITAL ABUSE.}

\section{By Lauriston E. SHAW, M.D. LoNd., F.R.C.P. LoNd. PHYSICIAY TO GUY'S HOSPITAL; HONORARY SECRETARY TO THE FACULTY OF MEDICINE OF THE LNIVERSITY OF LONDON; MEMBER OF THE CENTRAL HOSPITAL COUNCIL FOR} LOXNON.

THE discussion of hospital reform lately started by the British Medical Association, the impending removal of King's College Hospital from the centre of London to a populous suburb, the negotiations between the London Hospital and the surrounding medical practitioners, and the interest generally aroused in this subject at the present time would seem to make it desirable that any medical man who believes he sees a practicable remedy for hospital abuse should make it known to his colleagues. I therefore willingly accepted Dr. Robert Capes's invitation to take part in this discussion. In my remarks the term hospital abuse is intended to include the treatment at hospitals of patients unsuitable by reason either of their social position or of the nature of their ailments. I have taken a keen interest in this subject ever since, as a student, I was an unwilling instrument in carrying out what in the early eighties of last century was regarded as the most satisfactory way of preventing unsuitable cases from receiving hospital charity. I well remember after having distributed outpatient tickets to a small minority of a host of applicants escaping from the department by a window, in order that I might not see or hear the tears, prayers, and curses of the majority who were afterwards sent away by the porter without treatment. It must be a relief to all tliose interested in the welfare of the sick poor and in the reputation of our medical charities that this ancient method of dealing with the hospital problem is now generally discountenanced.

In the considerations that I propose to bring before you it will be assumed that hospital abuse as already defined exists and that the proposed remedies as recently set out for discussion by the Hospitals Committee of the British Medical Association are more or less familiar to those interested in

Being remarks made in a discussion on the subject before the Brixton Medical Society on Oct. 27th, 1904.: 
the subject. These proposals comprise the appointment the subject.
of investigation officers, the abolition of letters, the absence of payment for treatment, the refusal to see a second time accident cases in better-class patients, and one or two other minor features. I need not now refer more specifically to these proposals, for it is my chief object to point out that however desirable their adoption may be they will not secure their purpose unless supplemented by other more radical measures. It is the custom of public speakers when dealing with political problems to illustrate their arguments with such terms as correct diagnosis, transient symptoms, and vital disease, and to refer to their own proposals as rational treatment, while their political opponents are charlatans offering quack remedies to a suffering people. As a medical man speaking to medical men 1 may be allowed to follow this method of illustration, excluding, of course, all vituperation, and to state my belief that hospital abuse is but one of the symptoms of a general disease and that the treatment of it in the manner proposed is likely to accentuate the underlying pathological process. The tendency of unsuitable cases to crowd our hospitals is primarily due to the absence of satisfactory arrangements for the treatment by general practitioners of ordinary cases of illness arising amongst the lower and lower middle classes. The introduction of a ssstem whereby medical treatment in their own homes could be provided for all cases which do not need hospital treatment upon terms which would be satisfactory both to the general practitioner and the patient would go to the root of the difficulty and would at once reduce hospital abuse to such small dimensions that it could be easily dealt with.

I would first point out how ineffectual the mere local treatment of hospital abuse is likely to be even when every one of the proposals for local treatment formulated by the British Medical Association is put into practice. There is unfortunately no authority capable of enforcing the adoption and efficient carrying out of these proposals by all hospitals. As a consequence the patients driven from the larger and better conducted hospitals, which if good cause is shown will no doubt be quite willing to adopt the proposals, will almost certainly go to the less important institutions which will certainly refuse to adopt them. It is even to be feared that some enterprising people may see amongst the displaced patients material for the clientèle of hospitals newly founded for the constantly multiplying specialisms of the day. But even if some unexpected power should arise able to compel all hospitals to institute complete precautions against abuse of their charity, and also able to prevent the multiplication of unnecessary hospitals, it is by no means certain that the patients properly excluded from the hospitals would come under the care of those general practitioners who are honestly trying to do their best for their patients and to uphold the honour and reputation of their profession. The untrammelled practice of quacks and prescribing druggists and the unfortunate absence of any coöperation amongst members of the profession unhappily make it certain that great numbers of patients turned from the hospitals would either fall into the hands of unqualified practitioners or would provide a small number of medical men with further opportunities of employing those methods of unrestricted competition and underselling which are having such disastrous results in degrading the profession. So far it appears that the local treatment adopted would only drive the symptom, perhaps in an aggravated form, to another part of the body and at the same time increase the severity of the general condition. But there is a still further complaint to be made against these proposals for local treatment. From the very nature of the case the local treatment cannot be thoroughly effective even in removing the symptom. No amount of activity on the part of almoners or medical officers in investigating cases at the hospital can secure that the most suitable cases are admitted or treated. It is not enough to know what ails the patient or what he says he earns. Knowledge as to home surroundings and accommodation, availability and capability of relatives to act as nurses, the patient's obedience to orders, and on many other points is essential if a serious attempt is to be made to place the resources of our hospitals at the disposal of those only who really need them. And this knowledge of home conditions must be combined with a knowlecige of the patient's medical state and with an ability roughly to forecast the progress of his illness. It is impossible to avoid hospital abuse except by the assistance of a medical man who knows the patient in his home. But here we are met by the difficulty presented by the absence of satisfactory arrangements for the home troatment by gencral practitioners of the great mass of Loncloners who belong to the class likely when very seriously ill to require ho-pital treatment. A great number of these people have become so accustomed to take their trivial ailments to a hospital or other medical charity that there is no practitioner with any knowledge of their bome conditions. With the present fierce competition amongst medical men for the grachally diminishing number of persons who do not use hospitals, it is unlikely that any hospital authority would be disposed to place in their hands the responsible duty of selecting cases for hospital treatment. 'I'hus we see that our general disease (the absence of satisfactory arrangements for tie treatment in their homes of the lower and lower middle classes) is both the main cause of the symptom we are considering (hospital abuse) and is also the main obstacle to its satisfactory treatment.

It is often the physician's duty to point out that the treatment of symptoms is unscientific and even hurtful and to be in the unfortunate position of having no more hopeful alternative treatment to propose. In the present case this is not so. T'o discover a remedy for the present chaotic condition of medical treatment among the poor one must first look to the cause. It is not due to any inherent wickedness in the medical profession or in the poor. It is the direct result of a social development which can by no means be regarded as unsatisfactory. There has in recent years been a very rapid growth of an independent working class no longer expecting their wealthier neighbours to succour them in sickness, but without sufficient resources themselves to pay a remunerative fee to a medical practitioner. The medical profession, actuated at first by charity and afterwards by necessity, has gradually reduced its fees until they have become quite inadequate either to pay for the service rendered or to inspire confidence in the recipient of the service. Notwithstanding the almost ridiculous dimensions to which these fees have been reduced there is a large number of respectable Londoners who are unable to pay them regularly during any long illness without ceasing to be able to provide the absolute necessaries of life. To meet the requirements of these the out-patient departments of hospitals have been allowed to develop to inordinate proportions and the proper function of the hospitals has been seriously interfered with.

It would have been better for both the profession and for the poor if opportunities had been given to such people as could not afford a proper medical fee to set aside a small sum each month when in health in order to insure medical attendance in sickness. Although this has been, and still is, done in some districts on a small scale, the conditions in the majority of cases are such as make the system unpopular both with patient and medical attendant. By introducing this system on a large scale, safeguarded by certain essential features and strengthened by the active coöperation of the great hospitals, there is little doubt that medical attendance could be properly provided for all but the pauper class on terms which would remunerate the profession far more satisfactorily than is the case at present. 'The immense sums which can be accumulated by the collection of small contributions are well illustrated by the financial success of industrial insurance societies. In order to achieve a sufficient popularity to enable the subject of hospital abuse to be effectively and speedily dealt with there are certain features which should be arranged for in any proposal for a provident system that may be adopted.

1. The scheme must be open to all medical practitioners willing to join who have resided in the neighbourhood a certain minimum length of time.

2. It must be open to all persons who may be regarded as unable to pay a reasonable fee for medical attendance during prolonged serious illness.

3. There must be a sliding scale of payments beginning at the ordinary sum now payable by club patients and gradually increasing. 'The scale must be in proportion to the applicant's wages or to his rent and must vary also in accordance with the number of his dependents.

4. The patient must be at liberty to select his medical adviser from amongst those who participate in the scheme but it must be open to the medical man to decline to attend. Either party must be able to make a change at certain stated intervals.

5. The medical man's remuneration from the fund must 
depend upon the number of patients actually attencled by him.

6. T'here must be a small pecuniary penalty (probably payment for medicine) each time a patient receives service from the medical man.

7. The management must be in the hands of a board on which the medical profession has predominant representation.

It is of course important in submitting any scheme of this sort not to introduce too wuch detail. The above details are, however, necessarily noticed because they inclicate absolutely essential features and enable those interested to see at once how some of the unpopular elements of club practice as at present carried on are to be avoided. When once it was arranged that every patient could according to his means secure by a small periodic payment medical attendance by a general practitioner, there would be no excuse for offering medical charity unless the case were obviously of so exceptional a charaster as to require exceptional experience for its diagnosis or treatment. Those who could not afford the minimum payment would obviously be fit subjects for relief under the Poor-law. The charitable public would probably be asked to supplement the weekly payments of those who made the minimum contributions and should be encouraged to help the poor to keep up their payments whilst out of work or ill. Ultimately, it would no doubt be reasonable to arrange that no patient should be considered as eligible for hospital treatment who was not a contributor to the provident fund and certified by his medical attendant as a fit subject; and the out-patient department would come to be used by the medical men participating in the scheme as a means of obtaining free consultations for their poorer patients who were provident members.

The prospect of medical attendants being used under these conditions to prevent disease rather than to cure it presents many attractions. So, too, does the possible use of the collectors as apostles of hygiene in their weekly or monthly visits to obtain the periodic contributions. It seems to be well worth the consideration of the medical men of South London whether they can organise some such scheme as this before the arrival in their midst of King's College Hospital. On the other hand, King's College and many other hospitals might well consider whether, with a view of securing the most suitable cases for their charities, they can offer some special advantages to members of provident dispensaries conducted on lines likely to be beneficial to the public and the profession. Finally, some of the more important provident institutions which seem to make but little headway at the present time might discuss whether they could in coopperation with the hospitals so alter their conditions as greatly to increase their membership and to become a more efficient means of relieving the hospitals from the intolerable strain of the pressure of unsuitable cases commonly called hospital abuse.

\section{Lookíng JBack.}

\section{FROM \\ THE LANCET, SATURDAY, Des. 2, 1826.}

\section{FOREIGN DEPARTMENT. \\ ANATOMY.}

Absence of the Gall Bladder in a Human Liver. By M. GoDELIER, Surgeon-in-Chief of the Military Hospitals of the Rochelle.*

LEMERY mentions the case of a liver without the gallbladder, but it was thought that this state was owing to disease, rather than a natural conformation. Sabatier says, in his anatomy, that "the gall-bladder is never wanting in man; if, occasionally, it has been.thought that the contrary has been observed, it may be explained by the minute size of this organ, or its being sunk into the substance of the liver, or its being wasted by some disease." We are inclined to believe that the original deficiency of an organ is a much rarer occurrence than is generally believed; but Sabatier's assertion is by far too general, and admits of being easily refuted. The gall-bladder is the constant seat of disease; its cavity is frequently distended to an enormous size, and, on the other hand, sometimes quite obliterated. The obliteration of the cavity in the human subject, shows that the organ is not essential to life. And the entire absence of the gall-bladder in many animals, particularly the invertcbrated, is a proof, by analogy, of this assertion. Meckel in his Handbuch der I'athologischen Anatomie, Bd. I. p. 607, mentions cases of the total absence of the gall-bladder in the human subject. Habert $t$ and liedemann $t$ saw cases of this kind, where there was not the slightest trace of a depression in the liver for the gall-bladder. 'The following case may also be quoted in proof of the point, thus showing that the gall-bladder is not absolutely necessary to life, and that without this organ a person may enjoy a good state of health.

The subject of the following case, a soldier, xt. 26, on the 10th of last September, fell from a height whilst in a state of intoxication, and was killed on the spot. He was immediately carried to the Amphitheatre of the Military Hospital of La Rochelle. The inspection of the body was soon afterwards made in my presence, and the medical men belonging to the regiment. On opening the abclomen I was immediately struck with the absence of the gallbladder, and that the yellow appearance of the arch of the abdomen, which usually exists, was not present. We then proceeded to a more minute examination of the part, and found that there was not the slightest tint of yellow in the concave surface of the liver, nor any vestige of a fossa. Surprised at this phenomenon. two able assistants were directed to dissect the hepatic duct with care. Its size was double that of the natural state* No trace of a cystic duct could be discovered. Lastly, to avoid the possibility of a mistake, the liver was removed from the body and examined, both internally and externally, but without discovering the least vestige of a gall-bladder. In short we are all perfectly convinced that, in this person, the gall-bladder never existed.

$\dagger$ Phil. Trans. No. 492, p. 93

Reil's Archiv. Bd. 5, s. 144

* In most of the cases on record of absence of the gall-bladder, a similar dilatation of the hepatic duct has been observed.-ED. $L$.

Central Midwives Board.-The members of the Central Midwives Board met on Nov. 24th at 6, Suffolkstreet, London, S.W., Dr. F. H. Champneys being in the chair. A letter was read from the honorary secretary of the Metropolitan Counties Branch of the British Medical Association inclosing a copy of a letter addressed by the branch to the London County Council and asking for the coopperation of the Board with the London County Council in obtaining powers from Parliament to pay registered medical practitioners when called in by midwives in emergencies. The Central Midwives Board agreed that statutory provision should be made for the payment of the services of a registered medical practitioner when called in by a midwife in accordance with the rules of the Board and it was stated that the Board had already forwarded a resolution to this effect to the Privy Council. A letter was read from the clerk of the Monmouthshire county council asking the Board's construction of the words, "otherwise than under the direction of a qualified medical practitioner." These words occur in the second subsection of Section 1 of the Midwives Act, and after some discussion it was agreed that a letter should be written to the Monmouthshire county council saying that the Central Midwives Board was unable to give a general answer because the matter was one on which no authoritative legal decision had been given. After consideration of applications for certificates the names of 1068 women were passed under Section 2 of the Act and ordered for entry on the Roll. The total number of midwives enrolled now amounts to 10,538 , of whom 6166 are registered as "women in bon $\hat{\alpha}$-tide practice before July, 1901," while 3411 hold the certificate of the Obstetrical Society of London. Miss J. Wilson moved, and Dr. C. J. Cullingworth seconded, the following motion, which was carried:-

That in order to carry out the resolution agreed on at the meeting of the Board on April 28 th it be resolved that the Board take steps forthwith for the appointment of a trained inspector willing to act under the provisions of the resolution.

Dr. Cullingworth then proposed the exclusion of the press from the meetings of the Board, upon which a debate followed which was postponed until an opportunity had been given for the practice of the General Medical Council to be considered. The Board adjourned to Dec. 1st. 